\title{
Low rate of positive margins and re-excision after partial mastectomy in highly selected breast cancer patients: A Chinese single-institution experience
}

\author{
Siyu Wu ${ }^{1, *}$, Yanyan Zhu ${ }^{2, *}$, Zhaozhi Yang ${ }^{3, *}$, Miao Mo ${ }^{4}$, Hongbo Gao ${ }^{5}$, Wentao Yang ${ }^{6}$, \\ Guangyu Liu ${ }^{1}$ \\ ${ }^{1}$ Department of Breast Surgery, Fudan University Shanghai Cancer Center, Department of Oncology, Shanghai Medical \\ College, Fudan University, Shanghai, P.R. China \\ ${ }^{2}$ Department of General Surgery, Jinshan Hospital, Fudan University, Shanghai, P.R. China \\ ${ }^{3}$ Department of Radiation Oncology, Fudan University Shanghai Cancer Center, Department of Oncology, Shanghai Medical \\ College, Fudan University, Shanghai, P.R. China \\ ${ }^{4}$ Clinical Statistics Center, Fudan University Shanghai Cancer Center, Department of Oncology, Shanghai Medical College, \\ Fudan University, Shanghai, P.R. China \\ ${ }^{5}$ Department of Radiology, Fudan University Shanghai Cancer Center, Department of Oncology, Shanghai Medical College, \\ Fudan University, Shanghai, P.R. China \\ ${ }^{6}$ Department of Pathology, Fudan University Shanghai Cancer Center, Department of Oncology, Shanghai Medical College, \\ Fudan University, Shanghai, P.R. China \\ *These authors have contributed equally to this work \\ Correspondence to: Wentao Yang, email: yangwt2000@163.com \\ Guangyu Liu, email: 18121299998@163.com \\ Keywords: low rate, positive margins, highly selected, partial mastectomy, Chinese \\ Received: June 29, $2016 \quad$ Accepted: December 27, $2016 \quad$ Published: January 17, 2017
}

\section{ABSTRACT}

A recent randomized controlled trial firstly demonstrated that cavity shaving significantly decreased the rate of positive margins and re-excision among partial mastectomy (PM) patients. However, it remains unknown whether cavity shaving should be routinely applied to Chinese breast cancer patients undergoing PM. A total of 408 PM patients undergoing 410 PMs among 1796 surgically treated breast cancer patients at Fudan University Shanghai Cancer Centre from January 2015 to June $\mathbf{2 0 1 5}$ were included in our study. Data were analysed with univariate or multivariate analysis. Overall, 11 of 410 cases $(2.7 \%)$ had positive margins postoperatively. Moreover, only $24.6 \%$ of the cases $(P<0.05)$ presented with ductal carcinoma in situ (DCIS), among whom $10.0 \%$ obtained positive margins. In multivariate logistic regression analysis, presence of mammographic calcifications was significantly associated with margin positivity $(P<0.05,0 R=6.06,95 \% C I$ : 1.53-23.91). In conclusion, cavity shaving during $P M$ should not be routinely performed in Chinese breast cancer patients, particularly in highly selected cases with a low prevalence of DCIS. PM patients with preoperative mammographic calcifications were more likely to have positive margins and might benefit more from cavity shaving.

\section{INTRODUCTION}

A series of important randomized controlled trials (RCTs) consistently demonstrated that partial mastectomy (PM) plus radiation therapy could achieve overall survival rates similar to mastectomy while improving patients' aesthetic and psychological outcomes established standard status of PM for early breast cancer [1,2].

In contrast to mastectomy patients, PM patients are more likely to develop local recurrence. The latest meta-analysis, EBCTCG in 2011, revealed that 
for PM patients, one cancer-related death could be avoided over 15 years for every 4 patients with breast cancer recurrence over 10 years [3, 4]. Additionally, further re-excision was always required subsequently, which would undoubtedly increase the patient burden regarding economic considerations and cosmetic outcomes. Obtaining a negative surgical margin, one of the strongest predictors of lack of tumour recurrence, is of great clinical benefit and should be achieved to ensure an expectably low rate of local recurrence after PM.

Recently, Chagpar et al. established that PM patients with cavity shaving have a remarkably decreased rate of positive margins and re-excision in a RCT [5], thus bringing an end to years of retrospective analyses regarding cavity shaving. However, whether cavity shaving should be routinely conducted in the context of a Chinese population remains an unaddressed issue. We sought to address the feasibility of margin shaving in Chinese breast cancer patients in this study describing a Chinese single-institution experience.

\section{RESULTS}

A total of 408 patients undergoing 410 PMs from January 2015 to June 2015 were enrolled in this retrospective single-institutional study.

\section{Clinicopathological characteristics}

In our cohort, the median age was 46 years (range 19-82 years), and the median tumour size was 1.5 cm. 350 of 410 patients $(85.4 \%)$ had palpable tumors preoperatively and DCIS components were present in 101 patients postoperatively, accounting for $24.6 \%$ of all PM patients (Table 1).

A total of 11 patients had positive margins in the final pathological findings (Table 1); of these patients, 6 underwent re-excision, including 4 who were converted to mastectomy and 2 with positive margins who required further resection. The remaining patients did not undergo further surgery. A significant difference was observed between patients with positive and negative margins in terms of the presence of mammographic calcifications (yes or no) as well as DCIS components.

\section{Univariate and multivariate analysis for positive margins}

Univariate analyses revealed that the presence of mammographic calcifications as well as presence of DCIS. A series of important randomized controlled trials (RCTs) were risk factors significantly associated with positive margins in the first cohort (Table 1,2).

\section{Multivariate analysis for positive margins}

Notably, for 110 patients presenting with and 280 patients without mammographic calcifications, the percentages of patients who presented with DCIS components were $37.3 \%$ and $19.3 \%$, respectively $(P<0.05)$ (Table 1). Considering that it was widely accepted that such a significant correlation between DCIS and mammographic calcifications as present in our study as well as previous reports, and diagnosis of DCIS was mostly obtained postoperatively, instead of DCIS, presence of preoperative mammographic calcifications was incorporated into multivariate analysis. As was shown in Table 2, multivariate analysis showed that the presence of mammographic calcifications was significantly associated with positive margins after $\mathrm{PM}(P=0.01, \mathrm{OR}=6.06,95 \% \mathrm{CI}$ : $1.53-23.91)$.

In addition, Table 3 showed the correlations between the features of mammographic calcifications and margin status in 96 patients whose information was available. However, no significant differences were observed between the calcification features including type, morphology, distribution, range and margin status. It was noted that only $4.9 \%$ of these patients had calcifications in the range of $>30 \mathrm{~mm}$.

\section{Change in the rate of $\mathrm{PM}$ in the past five years}

From January 2010 to June 2015, the PM rate rose steadily at our centre, increasing from $18.1 \%$ to $22.7 \%$, which is the highest PM rate at our centre during the past 5 years (Supplementary Table 1).

\section{DISCUSSION}

A recent RCT concluded that a significant reduction in the rate of positive margins and re-excision was demonstrated by PM patients with cavity shaving, bringing level I evidence to cavity shaving after years of persistent debate and changing the surgical management of PM treatment [6-8]. However, our study demonstrated that cavity shaving should not be routinely conducted in highly selected Chinese breast cancer patients due to the low rate of positive margins after an initial PM.

The highlights of our study include that it is the first study to investigate the feasibility of applying cavity shaving in Chinese breast cancer patients, and it further explored the associations among positive margins and highly selected PM patients in a Chinese population compared to foreign countries. Collectively, our results showed that cavity shaving should not be performed in highly selected Chinese breast cancer patients who undergo a PM.

First, it was noted that PM accounted for only $22.7 \%$ of the surgical procedures for primary breast cancer, in contrast to $60-70 \%$ in the US [9]. This finding is also consistent with our previous data obtained during 
Table 1: Clinicopathological characteristics of patients who underwent initial breast-conserving surgery categorised by margin status

\begin{tabular}{|c|c|c|c|c|}
\hline \multirow{2}{*}{ Variable } & \multirow{2}{*}{ N (Percent) } & \multicolumn{2}{|c|}{ Margin status } & \multirow{2}{*}{$P$ valu } \\
\hline & & Positive & Negative & \\
\hline Age (years) & & & & $>0.05$ \\
\hline Median & 46 & 42 & 46 & \\
\hline Range & $19-82$ & $38-77$ & $19-82$ & \\
\hline$\leq 40$ & $105(25.6 \%)$ & $3(2.9 \%)$ & $102(97.1 \%)$ & \\
\hline$>\mathbf{4 0}$ & $305(74.4 \%)$ & $8(2.6 \%)$ & $297(97.4 \%)$ & \\
\hline Palpable tumor & & & & $>0.05$ \\
\hline Yes & $60(14.6 \%)$ & $3(5 \%)$ & $57(95 \%)$ & \\
\hline No & $350(85.4 \%)$ & $8(2.3 \%)$ & $342(97.7 \%)$ & \\
\hline $\begin{array}{l}\text { Mammographic } \\
\text { calcifications }\end{array}$ & & & & $<0.05$ \\
\hline Yes & $110(26.8 \%)$ & $7(6.4 \%)$ & $103(93.6 \%)$ & \\
\hline No & $280(68.3 \%)$ & $4(1.4 \%)$ & $276(98.6 \%)$ & \\
\hline NA & $20(4.9 \%)$ & $0(0 \%)$ & $20(100 \%)$ & \\
\hline $\begin{array}{l}\text { Neo-adjuvant } \\
\text { therapy }\end{array}$ & & & & $>0.05$ \\
\hline Yes & $41(10 \%)$ & $0(0 \%)$ & $41(100 \%)$ & \\
\hline No & $369(90 \%)$ & $11(3.0 \%)$ & $358(97.0 \%)$ & \\
\hline \multicolumn{5}{|l|}{ Histologic type } \\
\hline Ductal & $373(91.0 \%)$ & $9(2.4 \%)$ & $364(97.6 \%)$ & \\
\hline Lobular & $9(2.2 \%)$ & $0(0 \%)$ & $9(100 \%)$ & \\
\hline Other & $21(5.1 \%)$ & $2(9.5 \%)$ & $19(90.5 \%)$ & \\
\hline NA & $7(1.7 \%)$ & $0(0 \%)$ & $7(100 \%)$ & \\
\hline Presence of DCIS & & & & $<0.05$ \\
\hline Yes & $101(24.6 \%)$ & $10(10.0 \%)$ & $91(90.0 \%)$ & \\
\hline No & $309(75.4 \%)$ & $1(0.3 \%)$ & $308(99.7 \%)$ & \\
\hline Tumour size (cm) & & & & $>0.05$ \\
\hline Median & 1.5 & 1.2 & 1.5 & \\
\hline Range & $0-4$ & $1-3.5$ & $0-4$ & \\
\hline$\leq 2$ & $331(80.7 \%)$ & $8(2.4 \%)$ & $323(97.6 \%)$ & \\
\hline$>2$ & $76(18.5 \%)$ & $2(2.6 \%)$ & $74(97.4 \%)$ & \\
\hline NA & $3(0.8 \%)$ & $1(33.3 \%)$ & $2(66.7 \%)$ & \\
\hline Lymph node status & & & & $>0.05$ \\
\hline Positive & $93(22.7 \%)$ & $1(1.1 \%)$ & $92(98.9 \%)$ & \\
\hline Negative & $313(76.3 \%)$ & $10(3.2 \%)$ & $303(96.8 \%)$ & \\
\hline NA & $4(1.0 \%)$ & $0(0 \%)$ & $4(100 \%)$ & \\
\hline
\end{tabular}




\begin{tabular}{|c|c|c|c|c|}
\hline \multirow{2}{*}{ Variable } & \multirow{2}{*}{$\mathbf{N}$ (Percent) } & \multicolumn{2}{|c|}{ Margin status } & \multirow{2}{*}{$P$ value } \\
\hline & & Positive & Negative & \\
\hline $\begin{array}{l}\text { Lymphovascular } \\
\text { invasion }\end{array}$ & & & & $>0.05$ \\
\hline Positive & $78(19.0 \%)$ & $1(1.3 \%)$ & 77 (98.7\%) & \\
\hline Negative & $297(72.4 \%)$ & $10(3.4 \%)$ & $287(96.6 \%)$ & \\
\hline NA & $35(8.5 \%)$ & $0(0 \%)$ & $35(100 \%)$ & \\
\hline Histological grade & & & & $>0.05$ \\
\hline 1 & $12(2.9 \%)$ & $0(0 \%)$ & $12(100 \%)$ & \\
\hline 2 & $148(36.1 \%)$ & $2(1.4 \%)$ & $146(98.6 \%)$ & \\
\hline 3 & $140(34.1 \%)$ & $4(2.9 \%)$ & $136(97.1 \%)$ & \\
\hline High (pure DCIS) & $13(3.2 \%)$ & $1(7.7 \%)$ & $12(92.3 \%)$ & \\
\hline $\begin{array}{l}\text { Median (pure } \\
\text { DCIS) }\end{array}$ & $18(4.4 \%)$ & $1(5.6 \%)$ & $17(94.4 \%)$ & \\
\hline Low (pure DCIS) & $12(2.9 \%)$ & $0(0 \%)$ & $12(100 \%)$ & \\
\hline Other & $67(16.3 \%)$ & $3(4.5 \%)$ & $64(95.5 \%)$ & \\
\hline NA & $11(2.7 \%)$ & $0(0 \%)$ & $11(100 \%)$ & \\
\hline ER status & & & & $>0.05$ \\
\hline Negative & $111(27.1 \%)$ & $4(3.6 \%)$ & $105(96.4 \%)$ & \\
\hline Positive & $297(72.4 \%)$ & $7(2.4 \%)$ & $290(97.6 \%)$ & \\
\hline NA & $2(0.5 \%)$ & $0(0 \%)$ & $2(100 \%)$ & \\
\hline PR status & & & & $>0.05$ \\
\hline Negative & $133(32.4 \%)$ & $7(5.3 \%)$ & $126(94.7 \%)$ & \\
\hline Positive & $275(67.1 \%)$ & $4(1.5 \%)$ & $271(98.5 \%)$ & \\
\hline NA & $2(0.5 \%)$ & $0(0 \%)$ & $2(100 \%)$ & \\
\hline HER-2 status & & & & $>0.05$ \\
\hline Negative & $330(80.5 \%)$ & $9(2.7 \%)$ & $321(97.3 \%)$ & \\
\hline Positive & $76(18.5 \%)$ & $2(2.6 \%)$ & $74(97.4 \%)$ & \\
\hline NA & $4(1.0 \%)$ & $0(0 \%)$ & $4(100 \%)$ & \\
\hline Ki-67 & & & & $>0.05$ \\
\hline Low $(\leq \mathbf{2 0} \%)$ & $204(49.8 \%)$ & $6(2.9 \%)$ & $198(97.1 \%)$ & \\
\hline High $(>20 \%)$ & $201(49.0 \%)$ & $5(2.4 \%)$ & $196(97.6 \%)$ & \\
\hline NA & $5(1.2 \%)$ & $0(0 \%)$ & $5(100 \%)$ & \\
\hline
\end{tabular}

NA: not accessed; DCIS: ductal carcinoma in situ; ER: oestrogen receptor; PR: progesterone receptor; HER-2: human epidermal growth factor receptor-2.

the past 5 years and, more importantly, with countrywide data reporting a PM rate of $11.9 \%$ [10]. In addition to the shortage of radiation equipment noted in Fan L's review [11] and the relatively small breast volume of Chinese women $[12,13]$, this large difference may be explained by the strict PM criteria commonly adopted at our centre and in China. We diligently eliminated patients with diffuse or extensive mammographic calcifications preoperatively, which might have partly contributed to the high selectivity for patients receiving a PM in our centre, thus the low rate of positive margins and re-excision. However, in the NCCN guideline, this is not an absolute PM contraindication in foreign countries where a second or even a third re-excision is allowed [14]. 
Table 2: Univariate and multivariate analysis for the factors of positive margins

\begin{tabular}{|c|c|c|c|c|}
\hline \multirow{2}{*}{ Factors } & \multicolumn{2}{|c|}{ Univariate } & \multicolumn{2}{|c|}{ Multivariate } \\
\hline & OR(95\%CI) & $P$ values & OR $(95 \% C I)$ & $P$ values \\
\hline \multicolumn{5}{|l|}{ Age(years) } \\
\hline$\leq 40$ & 1.00 & & 1.00 & \\
\hline$>\mathbf{4 0}$ & $0.92(0.24-3.50)$ & 0.90 & $0.67(0.16-2.78)$ & 0.59 \\
\hline \multicolumn{5}{|c|}{ Tumour size(cm) } \\
\hline$\leq 2$ & 1.00 & & 1.00 & \\
\hline$>2$ & $0.99(0.21-4.76)$ & 0.99 & $0.81(0.16-4.23)$ & 0.80 \\
\hline \multicolumn{5}{|c|}{$\begin{array}{l}\text { Mammographic } \\
\text { calcifications }\end{array}$} \\
\hline No & 1.00 & & 1.00 & \\
\hline Yes & $3.97(1.14-13.80)$ & 0.03 & $6.06(1.53-23.91)$ & 0.01 \\
\hline \multicolumn{5}{|c|}{$\begin{array}{l}\text { Lymphovascular } \\
\text { invasion }\end{array}$} \\
\hline No & 1.00 & & 1.00 & \\
\hline Yes & $0.42(0.05-3.39)$ & 0.42 & $0.47(0.05-4.52)$ & 0.51 \\
\hline \multicolumn{5}{|c|}{ Lymph node status } \\
\hline Negative & 1.00 & & 1.00 & \\
\hline Positive & $0.33(0.04-2.61)$ & 0.29 & $0.32(0.04-2.59)$ & 0.29 \\
\hline \multicolumn{5}{|l|}{ ER status } \\
\hline Negative & 1.00 & & 1.00 & \\
\hline Positive & $0.64(0.18-2.22)$ & 0.48 & $0.483(0.13-1.81)$ & 0.28 \\
\hline \multicolumn{5}{|c|}{ HER-2 status } \\
\hline Negative & 1.00 & & 1.00 & \\
\hline Positive & $0.95(0.20-4.49)$ & 0.95 & $0.755(0.15-3.86)$ & 0.74 \\
\hline \multicolumn{5}{|l|}{ Ki-67 } \\
\hline$\leq \mathbf{2 0 \%}$ & 1.00 & & 1.00 & \\
\hline$>20 \%$ & $0.68(0.19-2.44)$ & 0.55 & $0.874(0.19-4.10)$ & 0.86 \\
\hline
\end{tabular}

Chagpar at el. found that the presence and size of DCIS were both significantly associated with margin positivity [5]. Accordingly, the percentage of patients with DCIS components in the current study was only $24.6 \%$, which was significantly lower than the value of $72.3 \%$ in Chagpar's study [5], firmly illustrating that the high selectivity of PM patients employed in our study produced a low rate of positive margins.

As a result, in contrast to the $2.7 \%$ margin positivity following the first attempted PM in our study, a significantly higher rate of positive margins even after performing cavity shaving (19\%) was reported in the trial [5]. Similarly, the percentage of patients with positive margins following initial PM also ranged from 20\% to $40 \%$ in most previous analogous studies [15]. More importantly, an observational study based on a large population of 2206 patients in the US reported a $12.1 \%$ positive margin $(0.0-0.9 \mathrm{~mm})$ rate along with a rate of $22.9 \%$ for re-excision of the initial PM [14].

Of note, the existing phenomenon might also be largely attributed to the substantial differences in conditions and culture between China and other countries such as insurance, traditions, value concepts and other factors. Re-excision signifies re-hospitalization and undoubtedly an increased expense for patients and constitutes a psychological burden for surgeons [14]. Consequently, unlike our hospital, most hospitals in China choose intraoperative frozen section evaluation, as reported in the study by Chen K [16]. Therefore, a more conservative standard for PM was justifiably adopted at our centre because intraoperative pathological evaluation was too timeconsuming to meet the demands of the increasing numbers of breast cancer patients treated at our centre every year from 1833 cases in 2010 to 3678 cases in 2014. 
Table 3: Correlations between calcification features and margin status

\begin{tabular}{|c|c|c|c|c|c|}
\hline & & \multirow{2}{*}{$\mathrm{N}=96$} & \multicolumn{2}{|c|}{ Margin status } & \multirow{2}{*}{$P$ value } \\
\hline & & & Positive & Negative & \\
\hline \multirow[t]{4}{*}{ Calcification type } & Calcifications only & $38(39.6 \%)$ & $3(7.9 \%)$ & $35(92.1 \%)$ & $>0.05$ \\
\hline & $\begin{array}{l}\text { Calcifications with } \\
\text { mass }\end{array}$ & $33(34.4 \%)$ & $3(9.1 \%)$ & $30(90.9 \%)$ & \\
\hline & $\begin{array}{l}\text { Calcifications } \\
\text { with asymmetric } \\
\text { compactness }\end{array}$ & $10(10.4 \%)$ & $1(10.0 \%)$ & $9(90.0 \%)$ & \\
\hline & $\begin{array}{l}\text { Calcifications with } \\
\text { architectural distortion }\end{array}$ & $15(15.6 \%)$ & $0(0 \%)$ & $15(100 \%)$ & \\
\hline \multirow[t]{2}{*}{ Morphology } & Fine branching & $94(97.9 \%)$ & $7(7.4 \%)$ & $87(92.6 \%)$ & $>0.05$ \\
\hline & Pleomorphic & $2(2.1 \%)$ & $0(0 \%)$ & $2(100 \%)$ & \\
\hline \multirow[t]{4}{*}{ Distribution } & Clustered & $50(52.1 \%)$ & $6(12.0 \%)$ & $44(88.0 \%)$ & $>0.05$ \\
\hline & Regional & $4(4.2 \%)$ & $0(0 \%)$ & $4(100 \%)$ & \\
\hline & Linear & $9(9.4 \%)$ & $1(11.1 \%)$ & $8(88.9 \%)$ & \\
\hline & Segmental & $33(34.4 \%)$ & $0(0 \%)$ & $33(100 \%)$ & \\
\hline \multirow[t]{3}{*}{ Range } & $\leq 20 \mathrm{~mm}$ & $69(71.9 \%)$ & $6(8.7 \%)$ & $63(91.3 \%)$ & $>0.05$ \\
\hline & $>20 \mathrm{~mm}$ & $13(13.5 \%)$ & $1(7.7 \%)$ & $12(92.3 \%)$ & \\
\hline & NA & $14(14.6 \%)$ & $0(0 \%)$ & $14(100 \%)$ & \\
\hline
\end{tabular}

Given that it has been well accepted that most DCIS patients present with calcifications on preoperative mammography [17], we made several interesting observations. In our study, patients with calcifications were indeed more likely to present with DCIS. Correspondingly, a higher proportion of PM patients with palpable tumours than in Chagpar's study also indirectly indicated that fewer patients might have presented with preoperative mammographic calcifications in our study cohort. Most importantly, we also found that the presence of mammographic calcifications (yes or no) was significantly associated with positive margins $(\mathrm{OR}=6.1, \mathrm{P}<0.05)$. In our experience, surgeons have used caution in choosing patients with calcifications for PM, mostly choosing PM for calcifications $\leq 20 \mathrm{~mm}$ and particularly excluding those patients whose calcifications were $>30 \mathrm{~mm}$. This observation was also corroborated by the study data in that the patients with calcifications $>20 \mathrm{~mm}$ and $>30 \mathrm{~mm}$ accounted for only $15.9 \%$ and $4.9 \%$, respectively, of the total study population.

It was noteworthy that on the basis of such a low rate of positive margins after PM, some previous work regarding PM conducted in our centre revealed, to some extent, that an acceptable local control as well as overall survival could be obtained, despite of different patient population $[18,19]$.

Finally, we sought to analyse the associations between the features of the calcifications and margin status. No significant correlations were found between these factors, which might be attributable to the limited number of patients with positive margins. Therefore, this topic will be a possible focal point in the next investigative stage.

Therefore, taken together, we have indicated that cavity shaving should not be routinely performed in highly selected Chinese breast cancer patients with a low rate of DCIS who receive a PM. Moreover, PM patients with mammographic calcifications might tend to be present with DCIS, thus constituting a specific target population with a higher risk of positive margins. Intuitively but hypothetically, this specific group of PM patients might have undergone cavity shaving among the population of PM patients with higher margin positivity who were not highly selected preoperatively, such as those in Chagpar's and other foreign studies. However, this assumption should be further investigated in RCTs due to the lack of a direct comparison.

In retrospect, the limited number of patients with positive margins and missing data also lowered the power of the study conclusions. Moreover, the retrospective nature, which could result in various biases, was also an inherent disadvantage.

In conclusion, cavity shaving during PM should not be conducted in Chinese breast cancer patients with a low prevalence of DCIS. Patients with preoperative mammographic calcifications were more likely to have positive margins and, hypothetically, might have indications for cavity shaving during PM in foreign countries, which deserves further investigation in RCTs. 


\section{MATERIALS AND METHODS}

\section{Patients}

The inclusion criteria for this retrospective study encompassed the patients undergoing PM at Fudan University Shanghai Cancer Centre (FUSCC). The eligibility for PM was assessed by the surgeons following strict adherence to the relevant guidelines, that is, T1T2 stage with an expected good cosmetic outcome after PM or meeting such criteria after neo-adjuvant therapy. The absolute exclusion criteria encompassed patients with contraindications for radiation, extensive disease or diffuse mammographic calcifications (range $>30$ $\mathrm{mm}$ ), multifocal disease, unwillingness to undergo PM or clinically suspected inflammatory breast cancer. The exclusion criteria specified those PM patients without detailed information on surgical margin status.

We firstly reviewed the data with respect to the number of PMs and corresponding surgical procedures for the initial diagnosis of breast cancer from January, 2008 to June, 2015 at FUSCC. The latest data with percentage of PM patients from January, 2015 to June, 2015 in FUSCC remained the highest and was selected to analyse risk factors of positive margins after PM. Our study was approved by the independent ethical committee/ institutional review board of FUSCC. All patients were gave written informed consent before inclusion in this study.

\section{Surgical technique}

PMs for breast cancer patients were performed by one experienced and qualified surgeon. PM consisted of excision of the tumour and the surrounding tissue at least $1 \mathrm{~cm}$ away from the tumour, extending from the subcutis to the pectoral fascia. We did not perform cavity shaving in PM patients in our centre. The decision regarding whether to pursue further surgical intervention for positive margins was left solely to the initial surgeon's discretion.

\section{Pathology examination for margins}

The perpendicular inked margin technique, first proposed in 1986 [20] and accepted as a standard method for assessing margin status worldwide afterwards, has been used for margin status assessment at our centre since 2008. The breast specimen containing the tumour is oriented and inked with six different colours indicating each individual margin including superior, inferior, medial, lateral and anterior. The entire specimen is then sectioned perpendicular to the inked surface and submitted for microscopic examination. The exact distance between the tumour and each individually coloured inked margin is measured under a microscope and reported by the pathologist [21].

Margins were considered positive when the tumour involved the inked margin of the specimen in cases of invasive cancer or was within $1 \mathrm{~mm}$ of the inked margin for ductal carcinoma in situ.

Additional margins were also obtained for pathological evaluation due to intraoperative gross examination by the surgeon or by a stand-by pathologist. Intraoperative frozen section evaluation for selective PM margins was not routinely applied in our centre except in a very small number of cases (less than 3\%) when required by the surgeon (Figure 1).

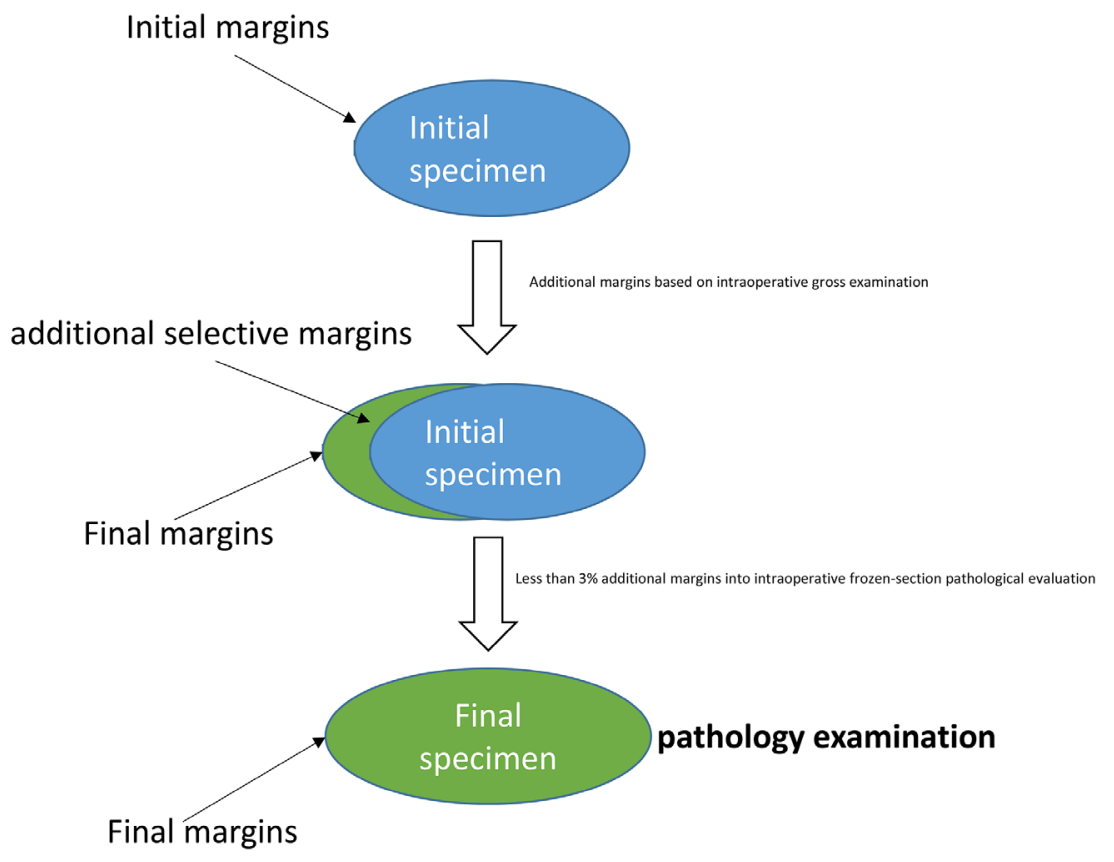

Figure 1: Surgical and pathological management of specimen and margins during and after PM. 


\section{Data collection}

The following demographic, clinical and pathological data for all the eligible patients was entirely extracted from the electronic medical records: age, preoperative mammographic calcifications, histological tumour size, histological grade, oestrogen receptor (ER), progesterone receptor (PR), human epidermal growth factor receptor-2 (HER-2), lymph nodal status, lymphovascular invasion status, and neo-adjuvant therapy. In our study, most patients with "mammographic calcifications" presented with the indicated malignant calcifications graded at least BI-RADS 4A on mammography, which were also pathologically validated before or after the PM. The detailed features of the calcifications were retrospectively analysed by a radiologist and a surgeon.

\section{Statistical analysis}

All of the included variables were deemed categorical variables and analysed using Pearson's or Fisher's exact test in univariate analysis.

In multivariate analysis, logistic regression analysis was used to evaluate the association between margin positivity and possible factors including age, tumour size, mammographic calcifications, lymph nodal status, ER, HER-2, Ki-67, and lymphovascular invasion status.

All statistical analyses were performed using SPSS statistical software version 18.0, with $\mathrm{p}$ values reported as two-sided with an alpha of 0.05 .

\section{ACKNOWLEDGMENTS}

This study was supported by grants from the Committee of Science and Technology of Jinshan (No. 2013-3-15).

\section{CONFLICTS OF INTEREST}

The authors declare that they have no conflicts of interest.

\section{REFERENCES}

1. Fisher B, Anderson S, Bryant J, Margolese RG, Deutsch M, Fisher ER, Jeong JH, Wolmark N. Twenty-year follow-up of a randomized trial comparing total mastectomy, lumpectomy, and lumpectomy plus irradiation for the treatment of invasive breast cancer. N Engl J Med. 2002; 347:1233-1241.

2. Veronesi U, Cascinelli N, Mariani L, Greco M, Saccozzi R, Luini A, Aguilar M, Marubini E. Twenty-year follow-up of a randomized study comparing breast-conserving surgery with radical mastectomy for early breast cancer. N Engl J Med. 2002; 347:1227-1232.
3. Darby S, McGale P, Correa C, Taylor C, Arriagada R, Clarke M, Cutter D, Davies C, Ewertz M, Godwin J, Gray R, Pierce L, Whelan T, Wang Y, Peto R. Effect of radiotherapy after breast-conserving surgery on 10-year recurrence and 15-year breast cancer death: meta-analysis of individual patient data for 10,801 women in 17 randomised trials. Lancet. 2011; 378:1707-1716.

4. McGale P, Taylor C, Correa C, Cutter D, Duane F, Ewertz M, Gray R, Mannu G, Peto R, Whelan T, Wang Y, Wang Z, Darby S. Effect of radiotherapy after mastectomy and axillary surgery on 10-year recurrence and 20-year breast cancer mortality: meta-analysis of individual patient data for 8135 women in 22 randomised trials. Lancet. 2014; $383: 2127-2135$.

5. Chagpar AB, Killelea BK, Tsangaris TN, Butler M, Stavris K, Li F, Yao X, Bossuyt V, Harigopal M, Lannin DR, Pusztai L, Horowitz NR. A Randomized, Controlled Trial of Cavity Shave Margins in Breast Cancer. N Engl J Med. 2015; 373:503-510.

6. Jacobson AF, Asad J, Boolbol SK, Osborne MP, BoachieAdjei K, Feldman SM. Do additional shaved margins at the time of lumpectomy eliminate the need for re-excision? Am J Surg. 2008; 196:556-558.

7. Hewes JC, Imkampe A, Haji A, Bates T. Importance of routine cavity sampling in breast conservation surgery. Br $\mathrm{J}$ Surg. 2009; 96:47-53.

8. Hequet D, Bricou A, Koual M, Ziol M, Feron JG, Rouzier R, Brouland JP, Delpech Y, Barranger E. Systematic cavity shaving: modifications of breast cancer management and long-term local recurrence, a multicentre study. Eur J Surg Oncol. 2013; 39:899-905.

9. Katipamula R, Degnim AC, Hoskin T, Boughey JC, Loprinzi C, Grant CS, Brandt KR, Pruthi S, Chute CG, Olson JE, Couch FJ, Ingle JN, Goetz MP. Trends in mastectomy rates at the Mayo Clinic Rochester: effect of surgical year and preoperative magnetic resonance imaging. J Clin Oncol. 2009; 27:4082-4088.

10. Zhang BL, Sivasubramaniam PG, Zhang Q, Wang J, Zhang B, Gao JD, Tang ZH, Chen GJ, Xie XM, Wang Z, Yang HJ, He JJ, Li H, Li JY, Fan JH, Wang X, et al. Trends in Radical Surgical Treatment Methods for Breast Malignancies in China: A Multicenter 10-Year Retrospective Study. Oncologist. 2015; 20:1036-1043.

11. Fan L, Strasser-Weippl K, Li JJ, St LJ, Finkelstein DM, Yu KD, Chen WQ, Shao ZM, Goss PE. Breast cancer in China. Lancet Oncol. 2014; 15:e279-e289.

12. Qiao Q, Zhou G, Ling Y. Breast volume measurement in young Chinese women and clinical applications. Aesthetic Plast Surg. 1997; 21:362-368.

13. Kayar R, Civelek S, Cobanoglu M, Gungor O, Catal H, Emiroglu M. Five methods of breast volume measurement: a comparative study of measurements of specimen volume in 30 mastectomy cases. Breast Cancer (Auckl). 2011; 5:43-52. 
14. McCahill LE, Single RM, Aiello BE, Feigelson HS, James TA, Barney T, Engel JM, Onitilo AA. Variability in reexcision following breast conservation surgery. JAMA. 2012; 307:467-475.

15. Pleijhuis RG, Graafland M, de Vries J, Bart J, de Jong JS, van Dam GM. Obtaining adequate surgical margins in breast-conserving therapy for patients with early-stage breast cancer: current modalities and future directions. Ann Surg Oncol. 2009; 16:2717-2730.

16. Chen K, Zeng Y, Jia H, Jia W, Yang H, Rao N, Song E, Cox $\mathrm{CE}$, Su F. Clinical outcomes of breast-conserving surgery in patients using a modified method for cavity margin assessment. Ann Surg Oncol. 2012; 19:3386-3394.

17. Dershaw DD, Abramson A, Kinne DW. Ductal carcinoma in situ: mammographic findings and clinical implications. Radiology. 1989; 170:411-415.

18. Li S, Yu KD, Fan L, Hou YF, Shao ZM. Predicting breast cancer recurrence following breast-conserving therapy: a single-institution analysis consisting of 764 Chinese breast cancer cases. Ann Surg Oncol. 2011; 18:2492-2499.

19. Yang Z, Zhang L, Chen X, Ma J, Mei X, Chen J, Yu $X$, Guo X. Multibeam inverse intensity-modulated radiotherapy (IMRT) for whole breast irradiation: a single center experience in China. Oncotarget. 2015; 6:3506335072. doi: 10.18632/oncotarget.5278.

20. Fisher ER, Sass R, Fisher B, Gregorio R, Brown R, Wickerham L. Pathologic findings from the National Surgical Adjuvant Breast Project (protocol 6). II. Relation of local breast recurrence to multicentricity. Cancer-Am Cancer Soc. 1986; 57:1717-1724.

21. Wright MJ, Park J, Fey JV, Park A, O'Neill A, Tan LK, Borgen PI, Cody HR, Van Zee KJ, King TA. Perpendicular inked versus tangential shaved margins in breast-conserving surgery: does the method matter? J Am Coll Surg. 2007; 204:541-549. 